\title{
Inactivation of Brain myo-Inositol Monophosphate Phosphatase by Pyridoxal-5'-Phosphate
}

\author{
Dae Won Kim, Joung Woo Hong , Won Sik Eum, Hee Soon Choi, Soo Hyun Choi, So Young Kim, \\ Byung Ryong Lee, Jae Jin An, Sun Hwa Lee, Seung Ree Lee, Oh-Shin Kwon’, Hyeok Yil Kwon\$, \\ Sung-Woo Cho"l, Kil Soo Lee*, Jinseu Park and Soo Young Choi* \\ Department of Genetic Engineering and Research Institute for Bioscience and Biotechnology, Hallym University, \\ Chunchon 200-702, Korea \\ The Biochemistry Program, The Ohio State University, Columbus, Ohio 43210, USA \\ Department of Biochemistry, Kyungpook National University, Taegu 702-701, Korea \\ ${ }^{\S}$ Department of Physiology, College of Medicine, Hallym University, Chunchon 200-702, Korea \\ "Department of Biochemistry and Molecular Biology, University of Ulsan College of Medicine, Seoul 138-736, Korea.
}

Received 19 June 2004, Accepted 12 August 2004

\begin{abstract}
Myo-inositol monophosphate phosphatase (IMPP) is a key enzyme in the phosphoinositide cell-signaling system. This study found that incubating the IMPP from a porcine brain with pyridoxal-5'-phosphate (PLP) resulted in a time-dependent enzymatic inactivation. Spectral evidence showed that the inactivation proceeds via the formation of a Schiff's base with the amino groups of the enzyme. After the sodium borohydride reduction of the inactivated enzyme, it was observed that $1.8 \mathrm{~mol}$ phosphopyridoxyl residues per mole of the enzyme dimer were incorporated. The substrate, myo-inositol-1-phosphate, protected the enzyme against inactivation by PLP. After tryptic digestion of the enzyme modified with PLP, a radioactive peptide absorbing at $210 \mathrm{~nm}$ was isolated by reverse-phase HPLC. Amino acid sequencing of the peptide identified a portion of the PLP-binding site as being the region containing the sequence L-Q-V-S-Q-Q-E-D-I-T-X, where $X$ indicates that phenylthiohydantoin amino acid could not be assigned. However, the result of amino acid composition of the peptide indicated that the missing residue could be designated as a phosphopyridoxyl lysine. This suggests that the catalytic function of IMPP is modulated by the binding of PLP to a specific lysyl residue at or near its substrate-binding site of the protein.
\end{abstract}

Keywords: Myo-inositol monophosphate phosphatase, Peptide analysis, Pyridoxal-5'-phosphate, Reactive lysine residue

\footnotetext{
*To whom correspondence should be addressed.

Tel: 82-33-248-2112; Fax: 82-33-241-1463

E-mail: sychoi@hallym.ac.kr; lks@hallym.ac.kr
}

\section{Introduction}

The receptor-mediated catalysis of phospholipase $\mathrm{C}$ on phosphoinositides gives rise to inositol mono- and polyphosphates, which are sequentially dephosphorylated to inositol (Berridge, 1984; Abdel-Latif, 1986). Inositol monophosphate phosphatase (IMPP, EC 3.1.3.25) catalyzes inositol monophosphates to inositol, which is required for the resynthesis of phosphatidylinositol and polyphosphoinositides (Gee et al., 1988; Majerus, 1992). This is a crucial step in the recycling mechanism because all the pathways within the inositol lipid cycle as well as the de novo synthesis of inositol 1-phosphate from glucose 6-phosphate converge at this point to replenish the pool of free inositol (Mauck et al., 1980).

IMPP has been purified from a variety of sources including rat (Takimoto et al., 1985), bovine (Gee et al., 1988), and porcine brains (Kwon et al., 1993), as well as from lily pollen (Gumber et al., 1984). This enzyme is believed to be the most probable target of $\mathrm{Li}^{+}$when lithium chloride is used to treat manic-depressive patients (Hallcher and Sherman, 1980; Sherman et al., 1981; Berridge et al., 1982; Batty and Nahorski, 1987; Avissar et al., 1988; Godfrey et al., 1989). It has been reported that $\mathrm{Li}^{+}$inhibits the IMPP of the bovine brain at therapeutic concentrations (Hallcher and Sherman, 1980; Takimoto et al., 1985) and that $\mathrm{Li}^{+}$decreases the concentration of the free inositol and increases the inositol phosphate levels in the rat brain (Allison and Stewart, 1971; Allison et al., 1976). Although cDNA clones encoding the human, rat, and bovine brain enzymes had been isolated (Diehl et al., 1990; McAllister et al., 1992b), the molecular gene cloning, the functional and structural properties of porcine IMPP have not been reported. This study identified a 
regulatory site of the porcine brain IMPP by a combination of labeling with PLP and peptide analysis.

\section{Materials and Methods}

Materials The ammonium sulfate, bovine serum albumin, EDTA, $\beta$-glycerophosphate, D, L-myo-inositol-1-phosphate, pyridoxal-5'phosphate, 2-mercaptoethanol, $\mathrm{HClO}_{4}$, ammonium molybdate, and trisma base were purchased from Sigma Chemical Co. (St. Louis, USA). Mono-Q, Sephacryl S-200, Superose-6, Mono-S, and Phenyl-Superose were purchased from Pharmacia/LKB Ltd. (Uppsala, Sweden). All the other materials used were of the best reagent grade available. The fresh porcine brains were obtained from the Majang-dong Slaughter House (Seoul, Korea).

Enzyme purification and assay The IMPP from a porcine brain was purified according to the procedure described elsewhere (Kwon et al., 1993). The enzyme isolated using this procedure has a specific activity of 1.7 units $/ \mathrm{mg}$ at $37^{\circ} \mathrm{C}$ and migrates as a single protein on polyacrylamide gel electrophoresis. The protein concentration was determined using the Bradford procedure with bovine serum albumin as a standard (Bradford, 1976).

The enzyme activity was measured by a colorimetric determination of the Pi (Itaya and Ui, 1966) released as a result of the hydrolysis of $\beta$-glycerophosphate and myo-inositol-monophosphate (Meek et al., 1988). One unit of activity was defined as the amount of enzyme converting $1 \mu \mathrm{mol}$ of the substrate into the product in $1 \mathrm{~min}$ at $37^{\circ} \mathrm{C}$. The initial velocity data were fitted using a least squares method to the double reciprocal transformation of Eq. (1).

$$
V=\mathrm{V}_{\max }[\mathrm{S}] /\left(\mathrm{K}_{\mathrm{m}}+[\mathrm{S}]\right)
$$

Spectroscopic studies Spectrophotometric measurements were carried out using a double beam Kontron UVIKON 930 spectrophotometer. The fluorescence spectra were recorded on a Kontron SFM 25 spectrofluorimeter.

Modification of IMPP with PLP The purified enzyme was dialyzed against a $0.1 \mathrm{M}$ potassium phosphate buffer $(\mathrm{pH}$ 7.0) containing $1 \mathrm{mM}$ EDTA and was used immediately. $200 \mathrm{mM}$ PLP was freshly prepared in $0.01 \mathrm{M}$ of an imidazole buffer $(\mathrm{pH} 7.0)$ and kept on ice. The incubation mixture $(1 \mathrm{ml})$ contained IMPP $(5 \mu \mathrm{M})$, PLP $(50-300 \mu \mathrm{M})$ and $0.01 \mathrm{M}$ imidazole, $1 \mathrm{mM}$ EDTA. The reaction was initiated by adding PLP in the dark at $25^{\circ} \mathrm{C}$. All the solutions containing the PLP were protected from photolytic destruction using metal foil. At set intervals after initiating the inactivation, aliquots were withdrawn and the level of activity was measured. Where possible, a small sample volume $(2 \mu \mathrm{l})$ was used to minimize the artifact blanks due to the transfer of PLP.

In some experiments, the capacity of myo-inositol-1-phosphate to protect the enzyme against inactivation was examined by including it in the incubation mixture. If the myo-inositol-1-phosphate concentration was sufficient to affect the activity, separate control experiments were included to determine the appropriate value of the $100 \%$ zero time activity. The amount of the PLP residues bound to the enzyme, after $\mathrm{NaBH}_{4}$ reduction, was determined by measuring the increase in absorbance at $325 \mathrm{~nm}$ using the molar extinction coefficient of 9,710 $\mathrm{M}^{-1} \mathrm{~cm}^{-1}$ for 6-pyridoxyllysine. The number of PLP residues bound/mol enzyme was also determined by fluorescence spectroscopy at an exciting wavelength of $325 \mathrm{~nm}$ and an emission wavelength of $390 \mathrm{~nm}$.

Labeling of IMPP and tryptic digestion In order to identify the PLP-binding site, the enzymes were treated with PLP, as described above. The samples were reduced with $\left[{ }^{3} \mathrm{H}\right] \mathrm{NaBH}_{4}$, and dialyzed against $20 \mathrm{mM}$ Tris- $\mathrm{HCl}$ (pH 8.0). After dialysis at $4^{\circ} \mathrm{C}$ overnight, the samples were treated with $6 \mathrm{M}$ guanidium chloride in $20 \mathrm{mM}$ Tris- $\mathrm{HCl}$ (pH 8.0), $0.5 \mathrm{mM}$ EDTA and $1 \mathrm{mM}$ dithiothreitol, to give final enzyme concentrations of $1.5-2.0 \mathrm{mg} / \mathrm{ml}$. After incubating at $25^{\circ} \mathrm{C}$ for 2 hours, the samples were dialyzed against four changes of $50 \mathrm{mM} \mathrm{NH} \mathrm{HCO}_{3}$ and $0.1 \mathrm{mM} \mathrm{CaCl} 2(\mathrm{pH} 8.0)$ at $4^{\circ} \mathrm{C}$ overnight. The dialyzed samples were proteolyzed by adding $20 \mu \mathrm{g}$ of trypsin and kept at $25^{\circ} \mathrm{C}$ for 3 hours. Subsequently, $20 \mu \mathrm{g}$ of trypsin was added. After 3 hours at $25^{\circ} \mathrm{C}, 30 \mu \mathrm{g}$ of trypsin was added, and the digestion mixtures were kept overnight at $25^{\circ} \mathrm{C}$.

Purification of the peptide containing the modified residue The digestion mixtures were freeze/dried, suspended in $0.1 \%$ trifluoroacetic acid, and subjected to reverse-phase HPLC on a Vydac $\mathrm{C}_{18}$ column $(250 \mathrm{~nm} \times 4.6 \mathrm{~nm})$. The separation was performed with a linear gradient of acetonitrile (from 0 to $80 \%$ ) containing $0.1 \%$ trifluoroacetic acid for $60 \mathrm{~min}$ at a flow rate of $1 \mathrm{ml} / \mathrm{min}$. The absorbance of the fractions was measured at $310 \mathrm{~nm}$, and the radioactivity was determined using liquid scintillation counting. The peptide containing radioactivity was further purified on a Hypersil ODS column $(250 \mathrm{~nm} \times 4.6 \mathrm{~nm})$ in a linear gradient of acetonitrile (from 0 to $60 \%$ ) containing trifluoroacetic acid in $5.0 \mathrm{mM}$ sodium phosphate (pH 6.4) for $120 \mathrm{~min}$ at a flow rate of $0.5 \mathrm{ml} / \mathrm{min}$.

Amino acid analysis and peptide sequencing The radioactive peptide was hydrolyzed for $24 \mathrm{~h}$ in $6 \mathrm{M} \mathrm{HCl}, 0.1 \%$ thioglycolic acid at $110^{\circ} \mathrm{C}$ under vacuum. The amino acids derivatized with phenylisothiocyanate were identified and quantified by a HPLC (Waters) PICO-TAG system, using a NOVA-PAK $\mathrm{C}_{18}$ column at room temperature with a flow rate of $1 \mathrm{ml} / \mathrm{min}$. For the amino acid sequence analysis, the labeled peptide was subjected to automated Edman degradation on a Beckman Model $890 \mathrm{M}$ sequenator according to the manufacturers instructions.

\section{Results}

Inactivation of IMPP by PLP Incubating the IMPP with increasing PLP concentrations resulted in a progressive decrease in the enzymatic activity (Fig. 1). This inactivation followed pseudo-first-order kinetics with the PLP concentrations in the range $50-300 \mu \mathrm{M}$. The pseudo-firstorder rate constants obtained at each PLP concentration were plotted as a function of the PLP concentration (Fig. 1). The second-order rate constant determined from the slope of this plot for the inactivation of IMPP by PLP was $98 \mathrm{M}^{-1} \mathrm{~min}^{-1}$.

This inhibitory effect exerted by PLP was reversed by adding the compounds that react with the Schiff's base. This was demonstrated by an experiment where IMPP $(5 \mu \mathrm{M})$ was 


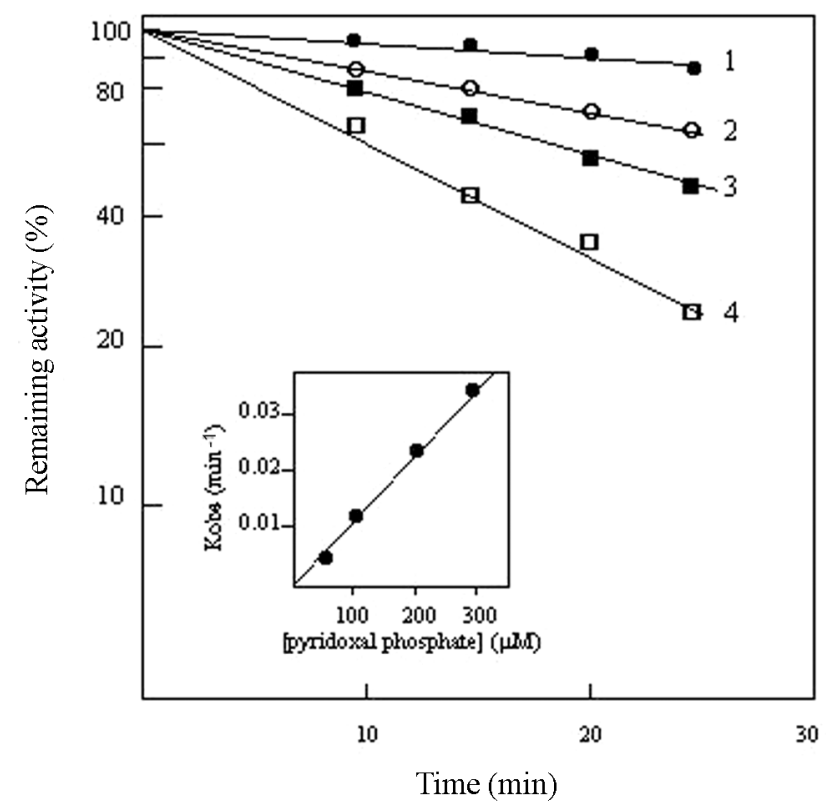

Fig. 1. Determination of the rate constant $\left(K_{\mathrm{obs}}\right)$ for the inactivation of myo-inositol monophosphate phosphatase at different pyridoxal-5'-phosphate (PLP) concentrations. The enzyme $(5 \mu \mathrm{M})$ was incubated with $50 \mu \mathrm{M}$ (1), $200 \mu \mathrm{M}$ (2), $300 \mu \mathrm{M}$ (3) and $400 \mu \mathrm{M}$ (4) of PLP in a $0.01 \mathrm{M}$ imidazole buffer ( $\mathrm{pH} 7.0$ ) at $25^{\circ} \mathrm{C}$ in the dark. The aliquots withdrawn from the incubation mixtures were examined for their enzymatic activity. The insert shows the dependence of the observed rate constant $\left(K_{\text {obs }}\right)$ on the PLP concentration.

Table 1. Inactivation of myo-inositol monophosphate phosphatase by pyridoxal-5'-phosphate (PLP)

\begin{tabular}{cc}
\hline Reaction mixture & $\begin{array}{c}\text { Remaining activity } \\
(\%)\end{array}$ \\
\hline Enzyme & 100 \\
Enzyme + PLP & 15 \\
Enzyme+myo-inositol-1-phosphate+PLP & 95 \\
\hline
\end{tabular}

$5 \mu \mathrm{M}$ enzyme, $300 \mu \mathrm{M}$ PLP and $3 \mathrm{mM}$ myo-inositol-1-phosphate were used.

incubated with $300 \mu \mathrm{M}$ PLP at $\mathrm{pH} 7.0$ for $30 \mathrm{~min}$ at $25^{\circ} \mathrm{C}$. The inactivated enzyme was then allowed to react with aminooxyacetate $(1.0 \mathrm{mM})$ for $30 \mathrm{~min}$ at $25^{\circ} \mathrm{C}$. Under these experimental conditions, the aminooxyacetate reacts with the free and bound PLP, and the IMPP recovered almost $90 \%$ of its original activity (data not shown). A similar recovery of the enzyme activity was observed when IMPP, which was incubated with PLP, was passed through a Sephadex G-25 column, which had been equilibrated with $0.01 \mathrm{M}$ imidazole buffer ( $\mathrm{pH} 7.0)$.

The inactivation studies were carried out using the substrates to define the sites of PLP modification. The reaction between the IMPP with PLP was almost blocked by incubating IMPP with the substrate myo-inisotol-1-phosphate (Table 1). The results of the UV-differential spectroscopic
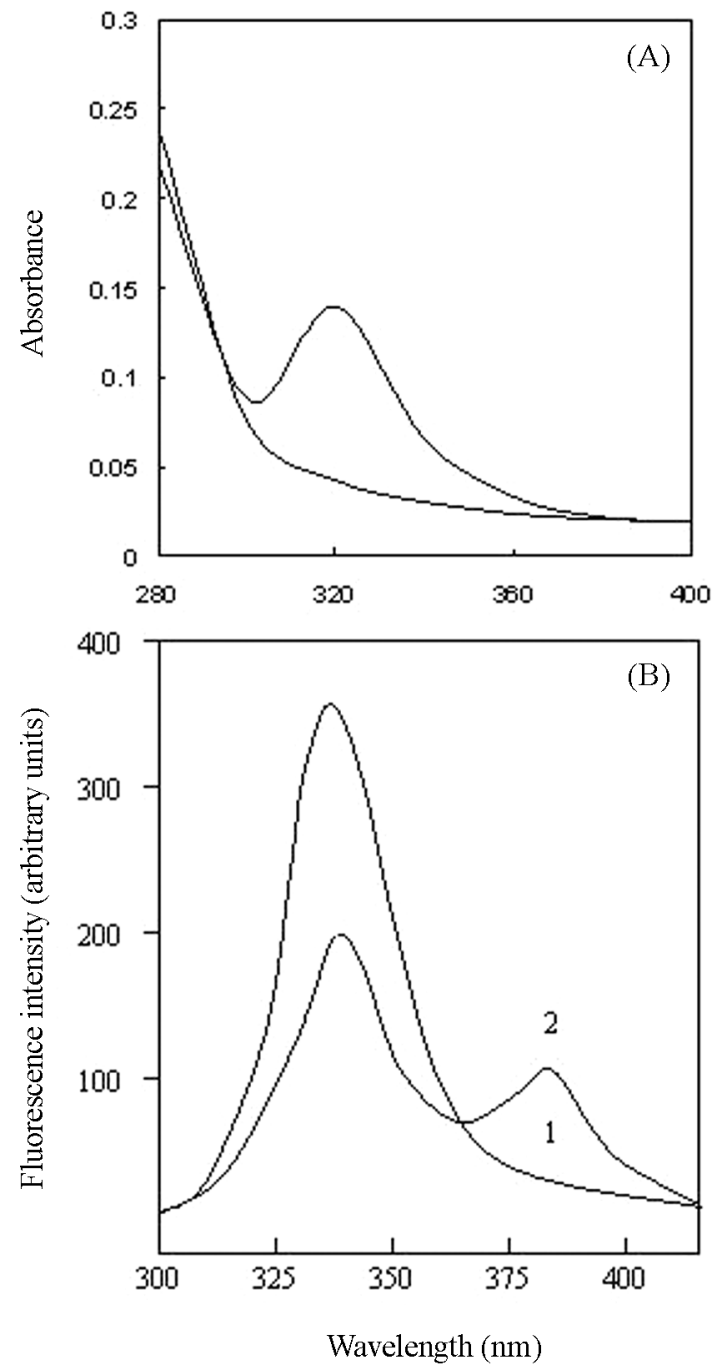

Fig. 2. (A) Absorption spectra of $300 \mu \mathrm{M}$ pyridoxal-5'-phosphate (PLP) treated (1) and the PLP treated-NaBH $\mathrm{N}_{4}$ reduced (2) myoinositol monophosphate phosphatase (IMPP). The reaction mixture was dialyzed against $20 \mathrm{mM}$ Tris- $\mathrm{HCl}$ buffer $(\mathrm{pH} 7.0)$ and the absorption spectra were determined, as described in Material and Methods. (B) Fluorescence emission spectra of the PLP treated (1) and PLP treated- $\mathrm{NaBH}_{4}$ reduced (2) IMPP. The reaction mixture was dialyzed against $20 \mathrm{mM}$ Tris- $\mathrm{HCl}$ buffer (pH 7.0) (Excitation wavelength: $280 \mathrm{~nm}$ ).

analysis of the interaction between the myo-inositol-1phosphate and PLP excluded the possibility that a 10-fold molar excess of myo-inositol-1-phosphate blocks the IMPP modification by a non-specific interaction with PLP (data not shown).

Spectroscopic properties In an effort to demonstrate that PLP is bound to the $\varepsilon$-amino groups of the protein, IMPP $(5 \mu \mathrm{M})$ was incubated with $300 \mu \mathrm{M}$ PLP at $\mathrm{pH} 7.0$ for $60 \mathrm{~min}$, reduced with $\mathrm{NaBH}_{4}$, and dialyzed against several changes of a $0.01 \mathrm{M}$ imidazole buffer ( $\mathrm{pH}$ 7.0). Studies on the $\mathrm{NaBH}_{4}$ reduction of the PLP-inactivated enzyme have provided 


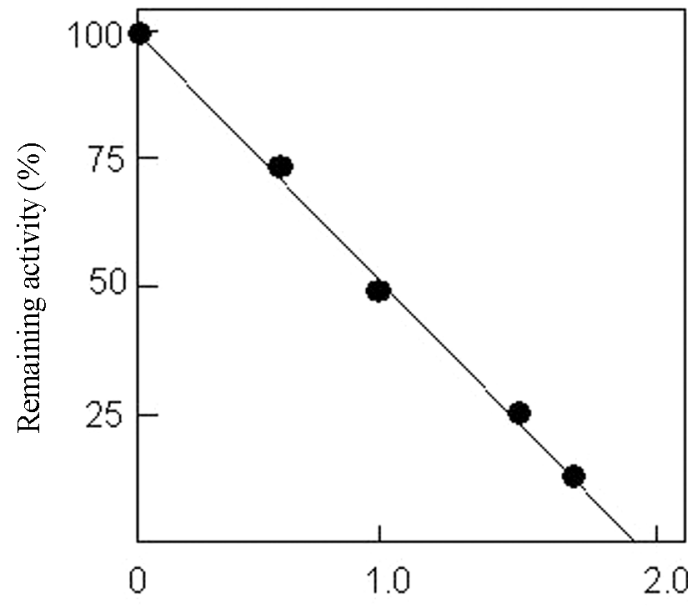

[Pyridoxal phosphate]/[Enzyme] ( $\mathrm{mol} / \mathrm{mol})$

Fig. 3. Stoichiometry of pyridoxal-5'-phosphate (PLP) inactivation. Myo-inositol monophosphate phosphatase (IMPP) $(5 \mu \mathrm{M})$ was incubated with $300 \mu \mathrm{M}$ of PLP in $20 \mathrm{mM}$ Tris-HCl buffer ( $\mathrm{pH}$ 7.0) at $25^{\circ} \mathrm{C}$ in the dark. The inactivation of IMPP is plotted as a function of the mol PLP incorporated/mol enzyme.

supporting evidence for formation of a primary Schiff's base during the inactivation process. After $\mathrm{NaBH}_{4}$ reduction of the PLP-inactivated enzyme, the dialysis of the modified IMPP did not restore its catalytic activity. This is in contrast to the complete restoration of the activity achieved by dialyzing the PLP-inactivated IMPP without $\mathrm{NaBH}_{4}$ reduction.

The spectrum of the reduced and dialyzed PLP-inactivated IMPP showed a characteristic peak at $325 \mathrm{~nm}$, which was absent from the spectrum of the native IMPP (Fig. 2A). The fluorescence spectrum of the pyridoxyl enzyme was completely different from that of the native IMPP when excited at $280 \mathrm{~nm}$. The pyridoxyl enzyme was characterized by two fluorescence peaks at 330 and $390 \mathrm{~nm}$, and the native IMPP exhibited a maximum emission peak at $330 \mathrm{~nm}$ (Fig. 2B), the intense absorption band at $325 \mathrm{~nm}$ corresponds to the phospho-pyridoxyl choromophore. The values for the incorporation of the reagents with or without protection by 3 $\mathrm{mM}$ myo-inositol-1-phosphate, were measured using an extinction coefficient of $9,710 \mathrm{M}^{-1} \mathrm{~cm}^{-1}$ at $325 \mathrm{~nm}$. PLP gave values of the overall incorporation of approximately $1.8 \mathrm{~mol}$ of phospho-pyridoxyl residues/mole enzyme dimer without protection and $0.2 \mathrm{~mol} / \mathrm{mol}$ with protection, indicating that 4 moles of the lysine residues per mol of enzyme were masked. Fig. 3 shows the correlation between the level of PLP incorporation and the enzyme activity. During the inactivation process, a linear relationship was observed between PLP incorporation and the reduced IMPP activity, which was extrapolated to a stoichiometry of $1.8 \mathrm{~mol}$ phospho-pyridoxyl residues/mole enzyme dimer, based on the increased absorbance at $325 \mathrm{~nm}$.

Isolation of the modified peptide In order to identify the
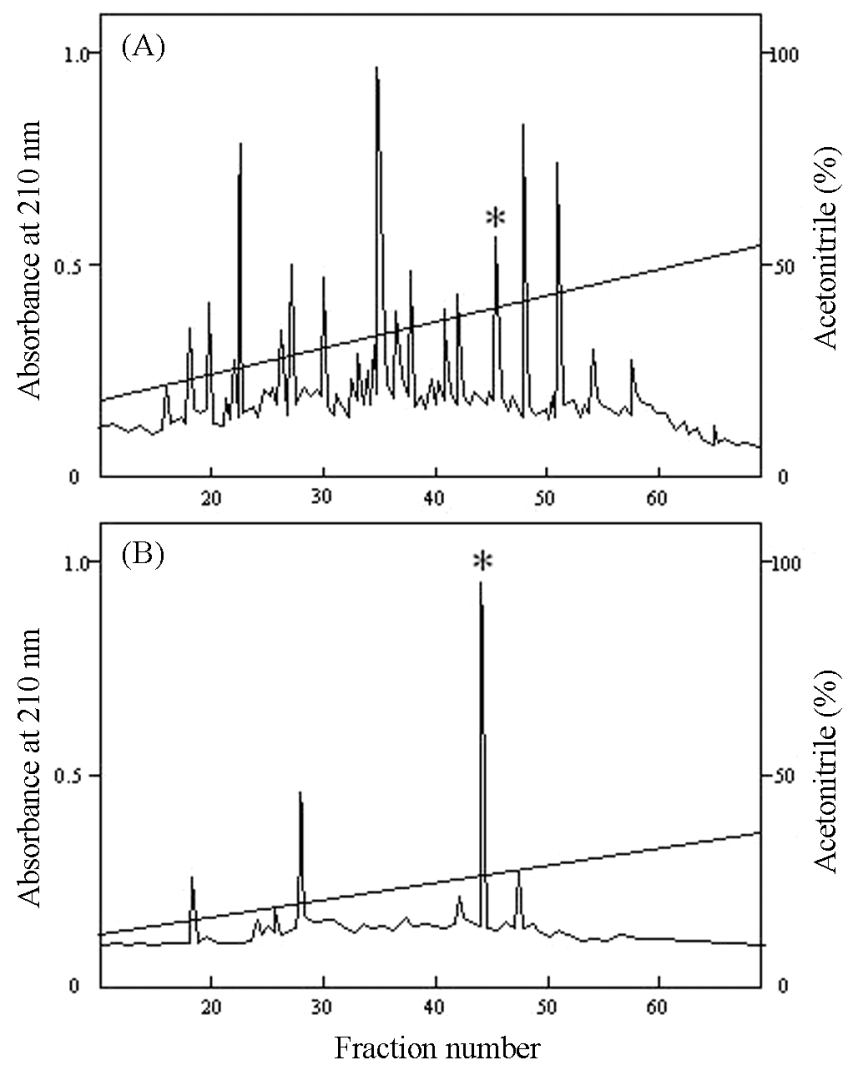

Fig. 4. (A) Separation of the tryptic peptides from modified myoinositol monophosphate phosphatase by reverse-phase HPLC. The separation was performed using a linear gradient from $0 \%$ (a) to $70 \%$ (b) in $60 \mathrm{~min}$ at a flow rate of $1 \mathrm{ml} / \mathrm{min}$ (a, $0.1 \%$ trifluoroacetic acid; $\mathrm{b}, 0.1 \%$ trifluoroacetic acid in acetonitrile/ $\mathrm{H}_{2} \mathrm{O}, 80: 20$ ) and monitored at $210 \mathrm{~nm}$. (B) Second HPLC chromatography of the tryptic peptides. The radioactive fractions labeled were pooled, lyophilized, and purified by reverse-phase HPLC (Hyper ODS) using a linear gradient of acetonitrile (0$60 \%$ ) containing $5 \mathrm{mM}$ sodium phosphate (pH 6.4) for $120 \mathrm{~min}$ at a flow rate of $0.5 \mathrm{ml} / \mathrm{min}$. The elution profile was monitored at $210 \mathrm{~nm}$. The radioactively labeled peptide (*) was sequenced by Edman degradation.

peptides modified by PLP, IMPP was reacted with PLP in the presence and absence of $3.0 \mathrm{mM}$ myo-inositol-1-phosphate, reduced with $\left[{ }^{3} \mathrm{H}\right] \mathrm{NaBH}_{4}$, denatured with guanidium chloride, and digested with trypsin under the conditions described above. After trypsin digestion of the PLP labeled IMPP overnight, the digested sample was loaded onto a reversephase column (Vydac $\mathrm{C}_{18}$ ). Only one major peptide absorbing at $210 \mathrm{~nm}$ was found to be radioactive (Fig. 4A), which suggests that the modification with PLP was restricted to a single amino acid in IMPP. The fractions showing an absorbance at $310 \mathrm{~nm}$ displayed a fluorescence maximum at $395 \mathrm{~nm}$ when recorded using a precision spectrofluorimeter (data not shown). When $3.0 \mathrm{mM}$ of myo-inositol-1-phosphate was present in the incubation mixture, more than $90 \%$ of the radioactivity and the peak absorbance at $310 \mathrm{~nm}$ was 
Table 2. Amino acid compositions of the pyridoxal-5'-phosphate (PLP) labeled peptides obtained after trypsin digestion of myoinositol monophosphate phosphatase. These values are ratios of the amino acids obtained after acid hydrolysis with $6 \mathrm{M} \mathrm{HCl}$ for $24 \mathrm{hrs}$ at $110^{\circ} \mathrm{C}$ in the presence of $0.1 \%$ thioglycolic acid. The values in parenthesis are the nearest integral ratios. The PLPlysine was determined as the 6-pyridoxyllysine using an $\varepsilon_{325}=$ $9,710 \mathrm{M}^{-1} \mathrm{~cm}^{-1}$.

\begin{tabular}{cc}
\hline Amino acid & Determined \\
\hline Asp & $1.20(1)$ \\
Glu & $0.92(1)$ \\
Ser & $0.89(1)$ \\
Thr & $1.11(1)$ \\
Val & $0.81(1)$ \\
Leu & $1.04(1)$ \\
Gln & $2.93(3)$ \\
Ile & $0.79(1)$ \\
Phosphopyridoxyl-Lys & $0.98(1)$ \\
\hline
\end{tabular}

eliminated (data not shown). This indicates that the radioactive peak represents a PLP-binding region within the brain IMPP.

The radioactive peak was further purified by reverse-phase chromatography on a Hypersil ODS column. One major radioactive peak (fractions 46-47) was recovered (Fig. 4B). Although some radioactivity was observed in the flow through and wash fractions, no amino acids were detected. Over $90 \%$ of the total radioactivity was eluted in the major radioactive peak (fractions 44-45).

Amino acid analysis and protein sequencing The amino acid composition of the labeled peak (Fig. 4B) is shown in Table 2. In order to identify the unknown amino acid as PLPlabeled lysine, the pyridoxyllysine was prepared as previously described (Anderson et al., 1996), and the elution time of the pyridoxyllysine was compared with that of the unidentified amino acid. The elution times of the two modified amino acids were identical, indicating that the unidentified amino acid was a pyridoxyl-modified lysine.

Amino acid sequence analysis revealed that the peak fractions contained the amino acid sequence, Leu-Gln-ValSer-Gln-Gln-Glu-Asp-Ileu-Thr-Xaa, where Xaa represents a phenylthiohydantoin amino acid that could not be assigned. This residue was identified as pyridoxyllysine by amino acid analysis, and trypsin could not cleave the labeled peptide at this site. Moreover, the labeling of this peptide was prevented by the presence of the $3.0 \mathrm{mM}$ myo-inositol-1-phosphate. These results strongly suggest that the lysine residue is located at or near the substrate-binding site of the porcine brain IMPP. The sequences obtained were also compared with those of the various IMPPs. As shown in Table 3, the amino acid sequence of the rat, human, bovine and porcine brain IMPP are the same except for one amino acid in the bovine IMPP, which indicates that the amino acid sequences reacting with PLP are well conserved.
Table 3. Alignment of the $\left[{ }^{3} \mathrm{H}\right] \mathrm{NaBH}_{4}$-labeled peptides with the homologous sequence from various IMPPs

\begin{tabular}{|c|c|c|}
\hline Source & Reference & $\begin{array}{l}\text { Amino acid } \\
\text { sequence }\end{array}$ \\
\hline Rat brain & McAllistar et al. & LQVSQQEDITK $^{(156)}$ \\
\hline Bovine brain & Diehl et al. & LQVSHQEDITK $^{(156)}$ \\
\hline Human brain & Sjoholt et al. & LQVSQQEDITK $^{(156)}$ \\
\hline Porcine brain & This work & LQVSQQEDITK \\
\hline
\end{tabular}

\section{Discussion}

Little of the chemistry of the active site of myo-inositol monophosphate phosphatase (IMPP) is known, which is to a certain extent due to there being no crystal structure of the enzyme available. Therefore, it is important that the detailed structure of IMPP be elucidated. Recently, IMPP was purified from a porcine brain homogenate (Kwon et al., 1993). The enzyme was a homodimer and an investigation of the catalytic role of the specific amino acid residues of the porcine brain IMPP indicated the involvement of a tryptophan residue in its enzymatic activity (Lee et al., 1999). This conclusion was reached based on evidence obtained by chemically modifying the enzyme with a tryptophan-specific modification reagent, N-bromosuccinimide (NBS). In this study, labeling with PLP and peptide analysis another identified regulatory residue of the porcine brain IMPP.

PLP is widely used in structural and functional studies to selectively label the particularly reactive lysyl residues, which are often directly involved in the catalytic actions active sites (Camardella et al., 1981; Dong and Fromm, 1990; Bello et al., 1992; Matsuyama et al., 1992). PLP contains an aromatic moiety and a negatively charged group, and these features are common to other lysyl-modifying reagents, which was discussed by Jeffery et al. (1985). Incubating the IMPP with increasing PLP concentrations resulted in a progressive decrease in enzyme activity (Fig. 1). PLP at concentrations of $300 \mu \mathrm{M}$ inhibited the reaction catalyzed by the IMPP. The requirement for phosphate, as well as the aldehyde group of PLP, for inhibition to occur is clearly shown by the fact that neither the pyridoxal nor pyridoxamine-5'-phosphate are effective inhibitors (data not shown). The evidence for the formation of a Schiff's base between PLP and lysine is provided by the finding that the addition of $\mathrm{NaBH}_{4}$ to the enzyme-PLP complex results in the incorporation of $\mathrm{P}$ pyridoxyl residues as revealed by the spectroscopic methods (Fig. 2).

The nature of the inhibitory effect exerted by PLP has been studied in detail. The possibility that PLP inhibition is the result of a reaction with the essential lysyl residues critically connected with catalysis was examined by performing inhibition studies in the presence and absence of the substrate myo-inositol-1-phosphate. The almost complete protection afforded by the myo-inositol-1-phosphate strongly suggests 
that the inactivation occurred due to an interaction with the lysyl residues located at or near the substrate binding site. Therefore, the myo-inositol-1-phosphate protects the enzyme from inactivation, but the phosphate ion does not (data not shown). These results suggest that either the substrate induces a conformation not accessible by the Pi-enzyme complex or that the site of modification by PLP is protected by the inositol moiety.

The fluorescence spectrum of the pyridoxyl enzyme differs completely from that of the native enzyme. The emission spectrum of the PLP-labeled IMPP displayed a maximum emission at approximately 330 and $390 \mathrm{~nm}$. The peak at 390 $\mathrm{nm}$ presumably arose through the transfer of an aromatic residue of the IMPP to the bound pyridoxyl group (Churchich, 1965). Moreover, this interpretation is consistent with the finding that the presence of pyridoxyl groups causes a dramatic quenching of the IMPP fluorescence. Although differences between the fluorescent intensities of the IMPP and pyridoxyl enzyme were observed by fluorescence spectroscopy, there was evidence showing that the conformational changes in IMPP did not occur when it reacts with PLP. This study investigated the conformational changes indirectly using fluorometric anisotrypy, but no differences were found in the anisotropies $(A)$ of IMPP $(A=0.178)$ and modified enzymes $(A=0.180)$. Based on the results of the inhibitory effect of PLP on IMPP and the almost complete protection afforded by the substrate, it is suggested that the inactivation occurs as a result of an interaction between PLP and the lysyl residue on IMPP, and not by the conformational changes induced in IMPP.

The IMPP isolated from the rat, bovine and human brain contains 17, 22 and 15 lysyl residues/mole dimer, respectively (Diehl et al., 1990; McAllistar et al., 1992a; Sjoholt et al., 1997). Although it is generally accepted that polar amino acids such as lysyl and arginyl residues are usually located on the surface of the protein molecules, the chemical modification results in this study show that only two lysine residues have a high reactivity with PLP, and that the other lysyl residues are relatively insensitive to modification. This suggests that the spectroscopic method of quantitative analysis for a number of reactive lysine residues may be affected by steric hindrance. Using the results from a comparison of the amino acid sequences obtained from the various IMPPs such as rat, human, bovine and porcine brain, the reactive lysine residue was found to be located at the 156 position in the brain IMPPs. However, in order to determine which lysine residue is involved in the catalysis and PLP binding, the three dimensional structures or site-directed mutagenesis studies of this enzyme will be needed.

In summary, this study clearly established that the porcine brain myo-inositol monophosphate phosphatase (IMPP) is modulated by the binding of pyridoxal-5'-phosphate (PLP) to a specific lysyl residue at or near its substrate binding site.

Acknowledgments This work was supported by a $21^{\text {st }}$
Century Brain Frontier Research Grant (M103KV01001903K2201-01910) and a National Research Laboratory Grant (M1-9911-00-0025) from the Ministry of Science and Technology, and in part by a Research Grant from Hallym University.

\section{References}

Abdel-Latif, A. A. (1986) Calcium-mobilizing receptor, polyphosphoinositide, and the generation of second messengers. Pharmarcol. Rev. 38, 227-272.

Allison, J. H. and Stewart, M. A. (1971) Reduced brain inositol in lithium-treated rats. Nature 233, 267-268.

Allison, J. H., Blisner, M. E., Holland, W. H., Hipps, P. P. and Sherman, W. R. (1976) Increased brain myo-inositol-1phosphate in lithium-treated rats. Biochem. Biophys. Res. Commun. 71, 664-670.

Anderson, B. M., Anderson, C. D. and Churchich, J. E. (1996) Inhibition of glutamic dehydrogenase by pyridoxal-5'phosphate. Biochemistry 5, 2893-2900.

Avissar, S., Schreiber, G., Danon, A. and Belmaker, R. H. (1988) Lithium inhibits adrenergic and cholinergic increases in GTP binding in rat cortex. Nature 331, 440-442.

Batty, I. and Nahoski, S. R. (1987) Lithium inhibits muscarinicreceptor stimulated inositol terakisphosphate accumulation in rat cerebral cortex. Biochem. J. 247, 797-800.

Bello, M. L., Petruzzelli, R., Lucia, R., Ricci, G., Barra, D. and Federici, G. (1992) Chemical modification of human placental glutathione transferase by pyridoxal-5'-phosphate. Biochim. Biophys. Acta 1121, 1384-1389.

Berridge, M. J. (1984) Inositol triphosphate and diacylglycerol as second messengers. Biochem. J. 220, 345-360.

Berridge, M. J., Downes, C. P. and Hanley, M. R. (1982) Lithium amplifies agonist-dependent phosphatidylinositol responses in brain and salivary glands. Biochem. J. 206, 587-595.

Bradford, M. (1976) A rapid and sensitive method for the quantitation of microgram quantities of protein utilizing the principle of protein-dye binding. Anal. Biochem. 72, 248-254.

Camardella, L., Romano, M., di Prisco, G. and Cancedda, F. D. (1981) Human erythrocytes glucose-6-phosphate dehydrogenase; labeling of a reactive lysyl residue by pyridoxal-5'-phosphate. Biochem. J. 103, 1384-1389.

Churchich, J. E. (1965) Energy transfer in protein pyridoxamine-5phosphate conjugates. Biochemistry 4, 1405-1410.

Diehl, R. E., Whiting, P., Potter, J., Gee, N. S., Ragan, C. I., Linemeyer, D., Schoepfer, R., Bennet, C. and Dixon, R. A. (1990) Cloning and expression of bovine brain inositol monophosphatase. J. Biol. Chem. 265, 5946-5949.

Dong, Q. and Fromm, H. J. (1990) Chemical modification of adenylosuccinate synthetase from Escherichia coli by pyridoxal-5-phosphate conjugates. J. Biol. Chem. 265, 62356240.

Gee, N. S., Ragan, C. I., Watling, K. J., Aspley, S., Jackson, R. G., Reid, G. G., Gani, D. and Shute, T. K. (1988) The purification and properties of myo-inositol monophosphatase from bovine brain. Biochem. J. 249, 883-889.

Godfrey, P. P., McClue, S. J., White, A. M., Wood, A. J. and Grahamesmith, D. G. (1989) Subacute and chronic in vitro 
lithium treatment inhibits agonist and sodium fluoridestimulated inositol phosphate production in rat cortex. $J$. Neurochem. 52, 498-506.

Gumber, S. C., Loewas, M. W. and Loewas, F. A. (1984) Further studies on myo-inositol-1-phosphatase from the pollen of Lilium longiflorum Thunb. Plant Physiol. 76, 40-44.

Hallcher, L. M. and Sherman, W. R. (1980) The effects of lithium ion and other agents on the activity of myo-inositol-1phosphatase from bovine brain. J. Biol. Chem. 255, 1089710901.

Itaya, K. and Ui, M. (1966) A new micro method for the colorimetric determination of inorganic phosphate. Clin. Chim. Acta 14, 361-366.

Jeffery, J., Hobbs, L. and Jornvall, H. (1985) Glucose-6-phosphate dehydrogenase from Saccharomyces cerevisiae: characterization of a reactive lysine residue labeled with acetylsalicylic acid. Biochemistry 24, 666-671.

Kwon, H. Y., Shin, H. C., Lee, Y. L., Cho, S.-W. and Choi, S. Y. (1993) Purification and properties of myo-inositol monophosphate phosphatase from porcine brain. Mol. Cells 3, 95-99.

Lee, B. R., Bahn, J. H., Jeon, S. G., Ahn, Y. K., Yoon, B. H., Kwon, H. Y., Kwon, O. S. and Choi, S. Y. (1999) Chemical modification of porcine brain myo-inositol monophosphate phosphatase by N-bromosuccinimide J. Biochem. Mol. Biol. 32, 294-298.

Majerus, P. W. (1992) Inositol phosphate biochemistry. Annu. Rev. Biochem. 61, 225-250.

Matsuyama, T., Soda, K., Fukui, T. and Tanizawa, K. (1992) Leucine dehydrogenase from Bacillus stearothermophilus: identification of active-site lysine by modification with pyridoxal phosphate. J. Biochem. 112, 258-265.

Mauck, J. L., Wong, Y. H. and Sherman, W. R. (1980) L-myoinositol phosphate synthetase from bovine testis: Purification to homogeneity and partial characterization. Biochemistry 19, 3623-3629.

McAllister, G., Whiting, P. J., Hammond, E. A., Knowles, M. R., Atack, T. R., Bailey, F. J., Maigetler, R. and Ragan, C. I. (1992a) Bovine inositol monophosphatase modification, identification and mutagenesis of reactive cystein residues. Biochem. J. 285, 461-468.

McAllister, G., Whiting, P., Hammond, E. A., Knowles, M. R., Atack, J. R., Bailey, F. J., Maigetter, R. and Ragan, C. I. (1992b) cDNA cloning of human and rat brain myo-inositol monophosphatase. Expression and characterization of the human recombinant enzyme. Biochem. J. 284, 749-754.

Meek, J. L., Rice, T. J. and Anton, E. (1988) Rapid purification of inositol monophosphate phosphatase from beef brain. Biochem. Biophys. Res. Commun. 156, 143-148.

Sherman, W. R., Leavitt, A. L., Honcher, M. P., Hallcher, L. M. and Phillips, B. E. (1981) Evidence that lithium alters phosphoinositides metabolism: Chronic administration elevates primarily D-myo-inositol-1-phosphate in cerebral cortex of the rat. J. Neurochem. 36, 1947-1951.

Sjoholt, G., Molven, A., Lovlie, R., Wilcos, A., Sikela, J. M. and Steen, V. M. (1997) Genomic structure and chromosomal localization of a human myo-inositol monophosphatase gene (IMPP). Genomics 45, 113-122.

Takimoto, K., Okada, M., Matsuda, Y. and Nakagawa, H. (1985) Purification and properties of myo-inositol-1-phosphatase from rat brain. J. Biochem. (Tokyo) 98, 363-370. 